\title{
Effect of Hospital Effluents on Physicochemical Characterization on Mbandaka River Water: A case study of River Botema Bofala Nkele of DRC
}

\author{
MATONDO FALANGA J. ${ }^{1}$, LIKOBA BOLOMBO J. ${ }^{2}$, KALONDA IKANA D. ${ }^{3}$, YONDO NGANDU V. ${ }^{4}$ \\ ${ }^{1-3}$ Department of Biology-Chemistry, Chemistry-Physics \& Geography and Management of the \\ Environment \\ ${ }^{1-3}$ Teaching Higher Institute \\ ${ }^{4}$ Department of Petrochemistry and Refining, University of Kinshasa \\ ${ }^{1-3}$ Mbandaka, Ecuador \\ DR Congo
}

\begin{abstract}
The present study consists with the physicochemical characterization of the effluents of the general hospital of reference of Mbandaka in the receiving medium which is the river Botema Bofala Nkele. It arises from the analyses carried out that water of the aforementioned river is polluted not only by the effluents of the hospital, but also from other not identified sources and that goes beyond the standard, especially upstream of the outlet of the hospital.

The analysis was carried out of parameters hereafter: temperature, $p H$, electric conductivity, dissolved oxygen, chemical request oxygenates some (DCO), biological request oxygenate some during 5 days (DBO5), Nitrate, suspended matter (MES) and sulphate.

The pollution of this river is confirmed by the high percentages of nitrate of about 40,66 $\mathrm{mg} / \mathrm{L}$ what proves a nitric pollution of studied water.

Strong organic load results in the DBO5 and the high DCO respectively reaching 48,30 $\mathrm{mg} / \mathrm{L}$ and $81,40 \mathrm{mg} / \mathrm{L}$.In addition, the sulphate gave a value of $871,30 \mathrm{mg} / \mathrm{L}$, which explains the value of the conductivity which reaches $169 \mu \mathrm{s} / \mathrm{cm}$ and the pH is 6,9.

The degree of contamination of this river located in which through the town of Mbandaka, differs from a site with another and according to the distance from distance of the source of pollution.
\end{abstract}

Key words: Characterization, Physicochemical, Water, Botema Bofala Nkele.

\section{INTRODUCTION}

The problem of waste, more especially of their management is of world topicality and their impact is perceived in several fields: environmental, installation, public health...The producing sources of waste are multiple. We can quote the households, industries, the hospital complexes... [1].

The hospital, actor of public health, must show the example hygiene prevention of the risks for the man and his environment. Reason for which, a close attention will have to be paid to the management of hospital waste so much solid that liquidate. That more especially as the latter are as well general as specific to the various medical departments as can contain a hospital complex.[2]

A hazardous or surface treatment of hospital waste is full of consequence on the environment and human health.

Unfortunately, generally, the report in the hospitals of the Town of Mbandaka is such as, waste resulting from the activities of these institutions of health are thrown in nature (river, rivers...). In certain cases, solid waste is either flee in the ground or incinerated with open sky (seldom in the suitable incinerator). As for the effluents, they are simply poured in the rivers or the septic tanks without a preliminary treatment. 
These effluents undoubtedly containing a certain proportion of the germs accumulate in the sediments and pollute the rivers receiving [3].

In the case of the general hospital of reference of Wangata, its effluents are poured directly in river BOTEMA BOFALA NKELE thus, our study consists in meeting only one principal need: Which is Chemical the Physico- characterization of water of river BOTEMA BOFALA NKELE receiving the effluents of the general hospital of reference of Wangata?

In connection with the question of research, we estimate that water of the river Botema Bofala Nkele receiving the effluents of HGR of Wangata should have a load in analyzed physicochemical parameters exceeding the limits required by the international standards.

Our study consists in making a physicochemical characterization of water of the river Botema Bofala Nkele receiving the effluents of HGR of Wangata. This characterization includes/understands the $\mathrm{pH}$, the suspended matter (MES), the chemical request oxygenates some (DCO), sulphate (SO2), nitrate (NO2), dissolved oxygen, electric conductivity, the biological request oxygenates some during 5 days (DBO5) and the temperature.

\section{MATERIALS AND METHODOLOGY}

\subsection{Medium of study}

The town of Mbandaka is the Chief town of the province of Ecuador, it is located at 0,252 of Northern latitude, 18o 15' 21 ' of longitude Is and its altitude is $312 \mathrm{~m}$ compared to the sea level. (the town hall of Mbandaka, 2016). According to the town hall of Mbandaka, its population is estimated at 1.032.000 Inhabitants in 2015. By considering that the town of Mbandaka has like ends BONGONDE and BAMANYA, an analysis of the distribution of the households makes it possible to evaluate the number of the households has 103.200.

Our study is based on the general hospital of reference of Wangata (HGRW) and in the river Botema Bofala Nkele. The HGRW is among the great medical institutions of the Town of Mbandaka and the Democratic Republic of Congo. It is located in the zone of Mbandaka health, on the Révolution avenue, with the number 2/A in the Boyera district, commune of Wangata, town of Mbandaka, Province of Ecuador, DR Congo.

The river Botema Bofala Nkele more precisely draws its source in the commune of Wangata in the district Mbandaka 3. It crosses the two communes of the town of Mbandaka where it several districts to throw itself in the Congo river.

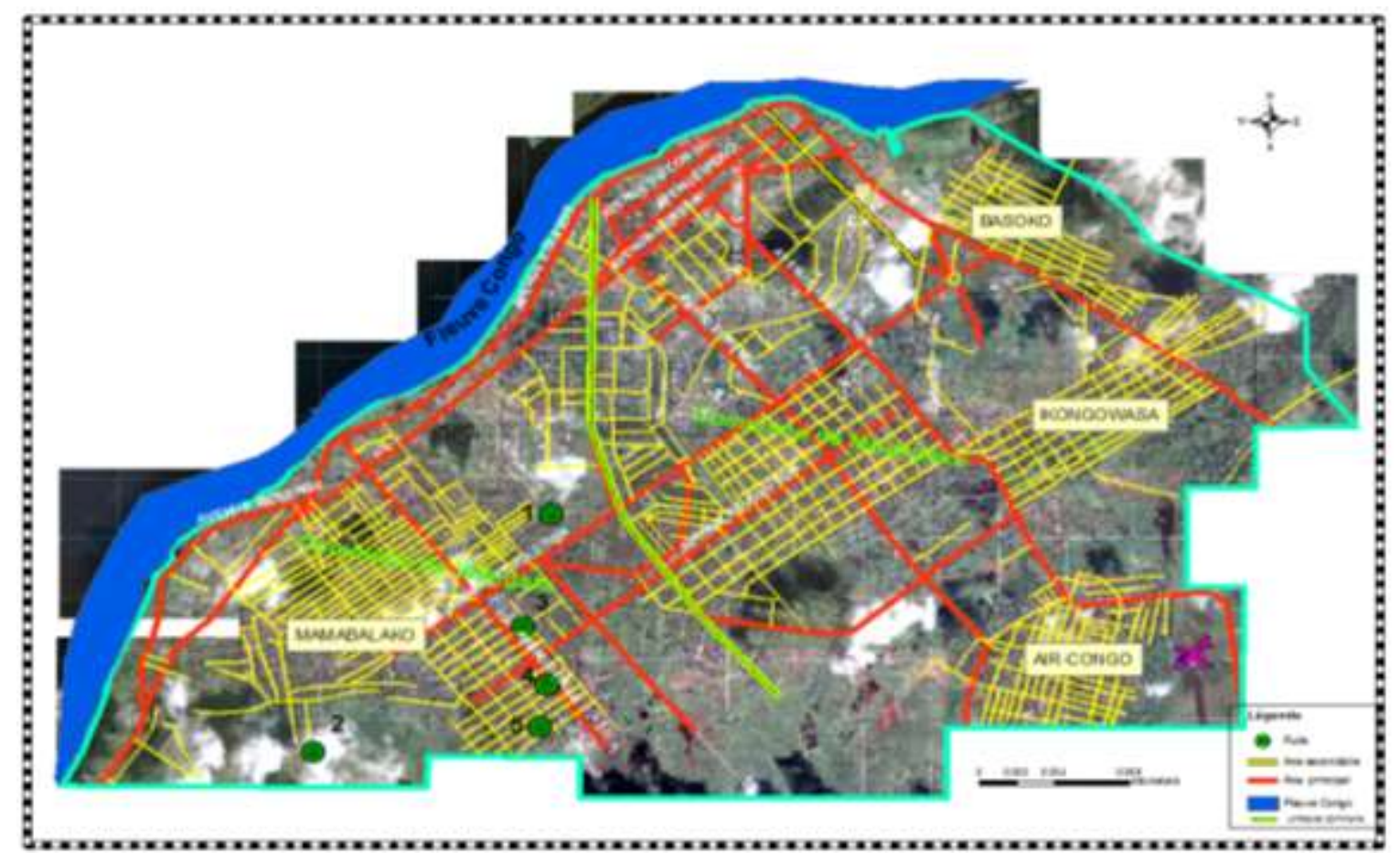

Figure 1: Cartography of Mbandaka

Source: The Red Cross of the DRC : provincial office of Ecuador 


\subsection{Sampling and mode of taking away}

At the time of this countryside, the taken water samples were put in polyethylene bottles of $500 \mathrm{ml}$, washed beforehand with the nitric acid then with distilled water. On ground, before the filling of the bottles, those - Ci were washed three times with water to be taken. The filling of the bottles was made to the brim then the stoppers hermetically closed in order to avoid any gaseous exchange with the atmosphere. The samples were collected between 9 hours and 12 hours, in accordance with the directives of the World Health Organization [4] and the recommendations of J. RODIER. The samples were taken between 30 and $50 \mathrm{~cm}$ of depth at the edge of the river [5].

These water samples were then transported in a refrigerator with $4 \mathrm{C}$ containing the ice floes, at the laboratory of the National Teaching University for analysis in the hour which follows the taking away. We had to target three sites of taking away:

$>$ Site A: Taken water with surroundings $100 \mathrm{~m}$ upstream of the outlet of the effluents of HGRW in the river Botema Bofala Nkele.

$>$ Site B: Water taken at the outlet of the liquid effluents of HGRW in the river Botema Bofala Nkele.

$>$ Site C: Taken water with surroundings $100 \mathrm{~m}$ downstream from the outlet of the effluents of HGRW in the river Botema Bofala Nkele.

\subsection{Methods of analysis}

Certain parameters were measured in situ:temperature, the $\mathrm{pH}$, conductivity, oxygen dissolves and suspended matter with two probes multi parameters of mark HANNA: Hi 9146 and Hi 991300.

The DCO given or was proportioned by spectrophotometry using a spectrophotometer UV - Visible of mark HACH DR. 2010. DBO5 or the quantity of oxygen consumed in 5 days (with 20C) by the micro-organisms ensuring the mineralisation of the organic matter present in water was proportioned by incubation starting from an incubator of the type HACH.

Concerning the anions: the sulphates and the nitrates were analyzed using a spectrophotometer UV according to the method described by RODIER [5].

\section{RESULTS AND INTERPRETATION}

\subsection{Presentation of the results}

Results of our physico analyses - chemical are synthesized in the table below:

Table 1: Value of the parameters measured in water

\begin{tabular}{|l|l|l|l|l|l|l|l|l|l|}
\hline $\begin{array}{l}\text { Sites of } \\
\text { taking away }\end{array}$ & $\mathrm{T}^{\circ} \mathrm{C}$ & $\mathrm{pH}$ & $\begin{array}{l}\mathrm{CE} \\
(\mu \mathrm{S} / \mathrm{cm})\end{array}$ & $\begin{array}{l}\mathrm{MES} \\
(\mathrm{mg} / \mathrm{L})\end{array}$ & $\begin{array}{l}\mathrm{O}_{2} \\
(\mathrm{mg} / \mathrm{L})\end{array}$ & $\begin{array}{l}\mathrm{NO}_{2} \\
(\mathrm{mg} / \mathrm{L})\end{array}$ & $\begin{array}{l}\mathrm{SO}_{2} \\
(\mathrm{mg} / \mathrm{L})\end{array}$ & $\begin{array}{l}\mathrm{DCO} \\
(\mathrm{mg} / \mathrm{L})\end{array}$ & $\begin{array}{l}\mathrm{DBO} \\
(\mathrm{mg} / \mathrm{L})\end{array}$ \\
\hline $\mathrm{A}$ & 24,7 & 6,90 & 168 & 84 & 14,80 & 18,06 & 642,11 & 76,04 & 45,61 \\
\hline $\mathrm{B}$ & 25,2 & 6,59 & 87 & 44 & 14,64 & 40,66 & 871,30 & 81,40 & 62,42 \\
\hline $\mathrm{C}$ & 24,3 & 6,85 & 169 & 84 & 14,39 & 28,12 & 438,52 & 68,32 & 48,30 \\
\hline $\begin{array}{l}\text { Standards' of } \\
\text { WHO }\end{array}$ & 25,0 & $6,5-8,5$ & 125 & 5 & $4-7$ & 50 & 400 & 20 & 6 \\
\hline
\end{tabular}

The figure below makes it possible to better determine the variations of the various physicochemical parameters taken in various sites of the river 


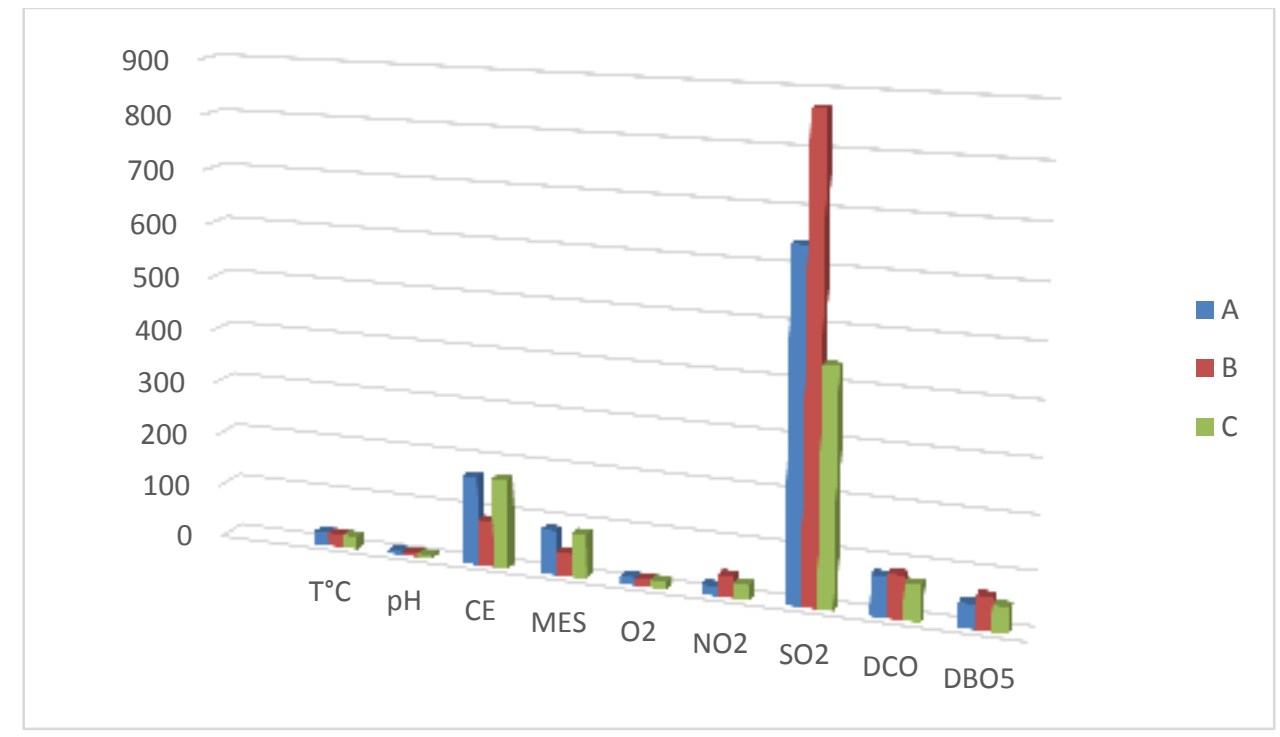

Figure 2: Value of the parameters measured in water

\subsection{Interpretation of the results}

The results of our analyses were compared according to standards' of the World Health Organization. The values of temperature recorded during our study vary between $24,7-25,2 \mathrm{C}$ with an average of $24,73 \mathrm{C}$. The minimal value $24,3 \mathrm{C}$ is recorded on the level of the site C, maximum the $26,60 \mathrm{C}$ is observed with the site $\mathrm{B}$.

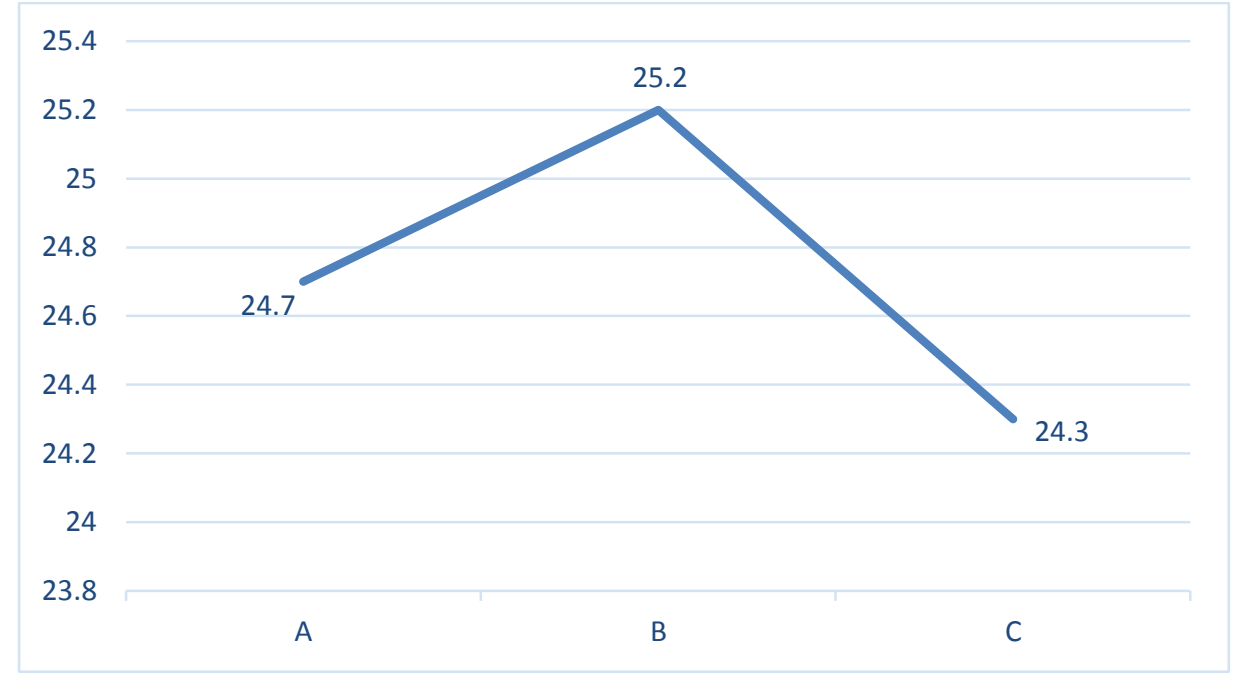

Figure 3: variation of temperature in the sites of taking away

This difference can be explained by the fact that the site B receives the worn water discharges of the hospital, while the site C receives the rejections of the other institutions and in addition water valves of the surrounding population. All these values are except standard, i.e. beyond and in on this side $25,00 \mathrm{C}$.

As for the $\mathrm{pH}$ all the values are included/understood between 6,59 and 6,90 with an average of 6,78. These values indicate that the $\mathrm{pH}$ of the studied sites are in conformity with the standards, limited between 6,5 to 8,5 . The low value is observed with the site $\mathrm{C}$, downstream from the outlet of the hospital. The variation of the $\mathrm{pH}$ is due probably to the contributions of worn water domestic and the rejections of the hospital. 
International Journal of Advances in Scientific Research and Engineering (ijasre), Vol 5 (11), November-2019

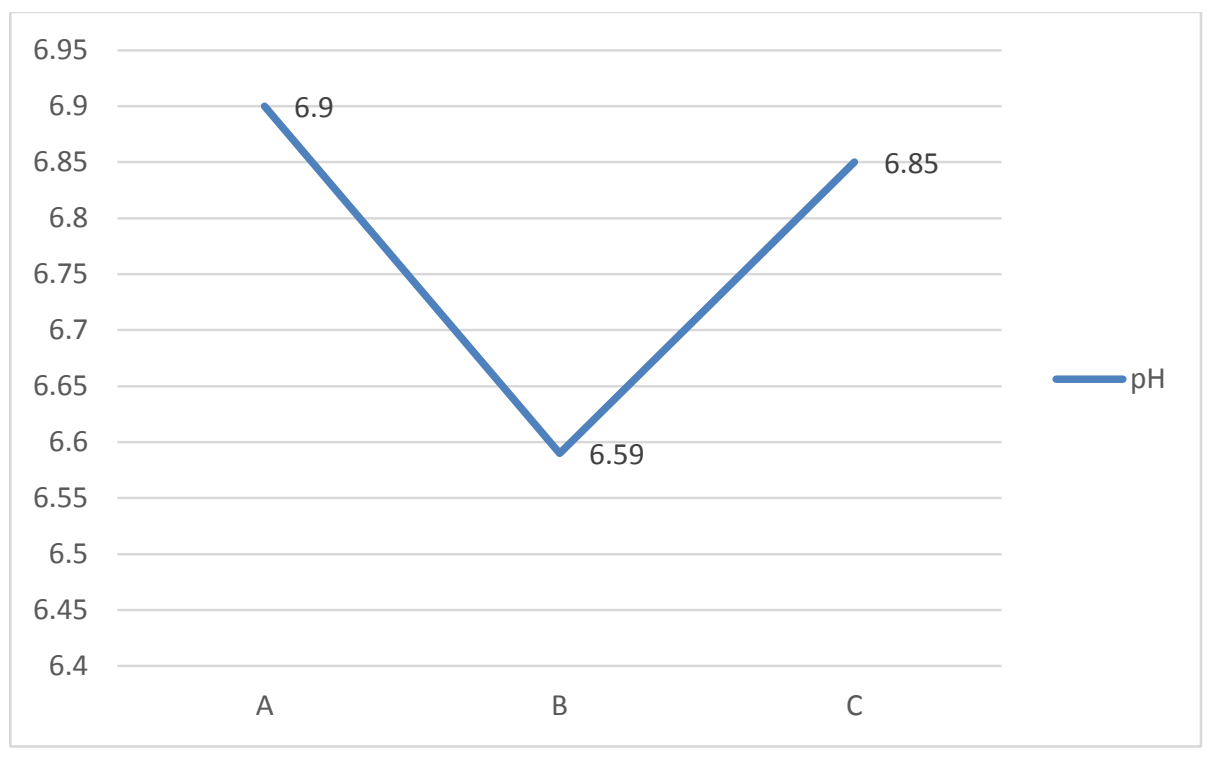

Figure 4: variation of $\mathrm{pH}$ in the sites of taking away

In addition, measured electric conductivities present values except standard, oscillating between $87 \mu \mathrm{s} / \mathrm{cm}$ and $169 \mu \mathrm{s} / \mathrm{cm}$ with an average observed of $141,3 \mu \mathrm{s} / \mathrm{cm}$. The sites B and C, mark the minimal and maximum values respectively. This high conductivity of this river is probably due to the presence of the strong dissolved salt concentration.

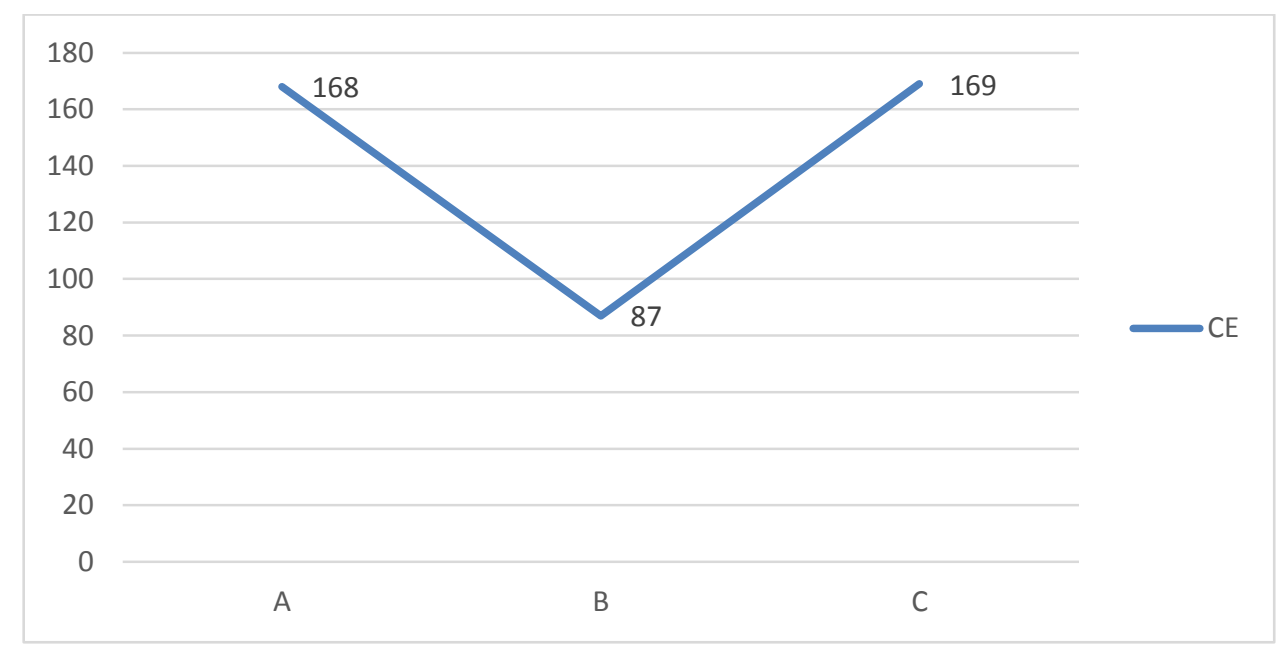

Figure 5: variation of electric conductivitie (CE) in the sites of taking away

The dissolved oxygen contents are beyond the standard. In the water of the river they vary between 14,39 $\mathrm{mg} / \mathrm{L}$ with $14,80 \mathrm{mg} / \mathrm{L}$, values recorded in the sites $\mathrm{C}$ and $\mathrm{A}$, with an average of $14,61 \mathrm{mg} / \mathrm{L}$. These relatively low contents show that there is an oxygen deficit, related to the rejections, as with the suspended matter which limits the penetration of the light in this river.

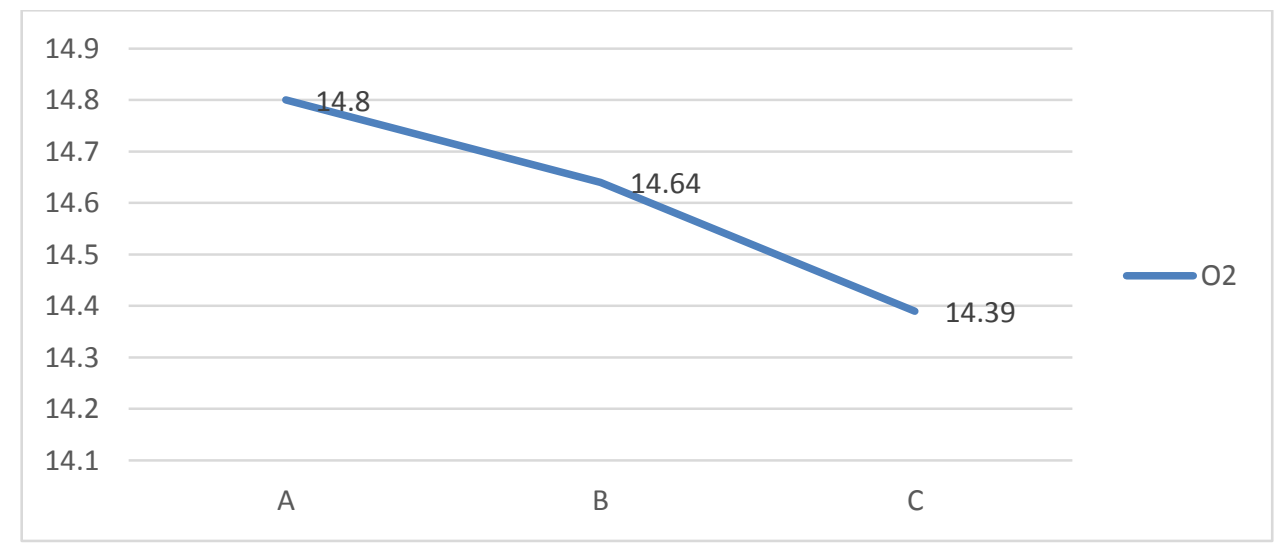

Figure 6: variation of dissolved oxygen content in the sites of taking away 
The suspended matter rate varies between $44,0 \mathrm{mg} / \mathrm{L}$ with $84,0 \mathrm{mg} / \mathrm{L}$, values recorded in sites A, B and C, with an average of $70,66 \mathrm{mg} / \mathrm{L}$. These contents relatively very high show that there is a good quantity of the dissolved matters, dependent on the rejections in this river which is a outfall of the town of Mbandaka.This suspended matter rise limits the penetration of the light in this river.

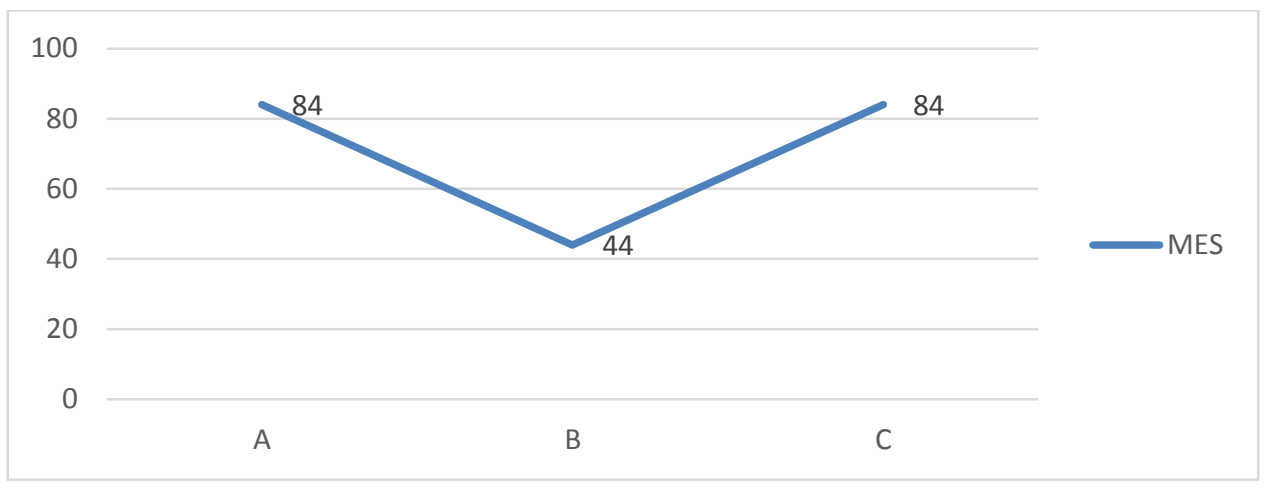

Figure 7: variation of suspended matter content in the sites of taking away

As for the anions: we measured the concentration of nitrates and the sulphates which present values 10 at 15 times higher than the standard. The highest value of nitrates is $40,66 \mathrm{mg} / \mathrm{L}$, observed at the outlet of the hospital, sulphates, the highest value is 871,30 $\mathrm{mg} / \mathrm{L}$ also observed at the outlet of the hospital.

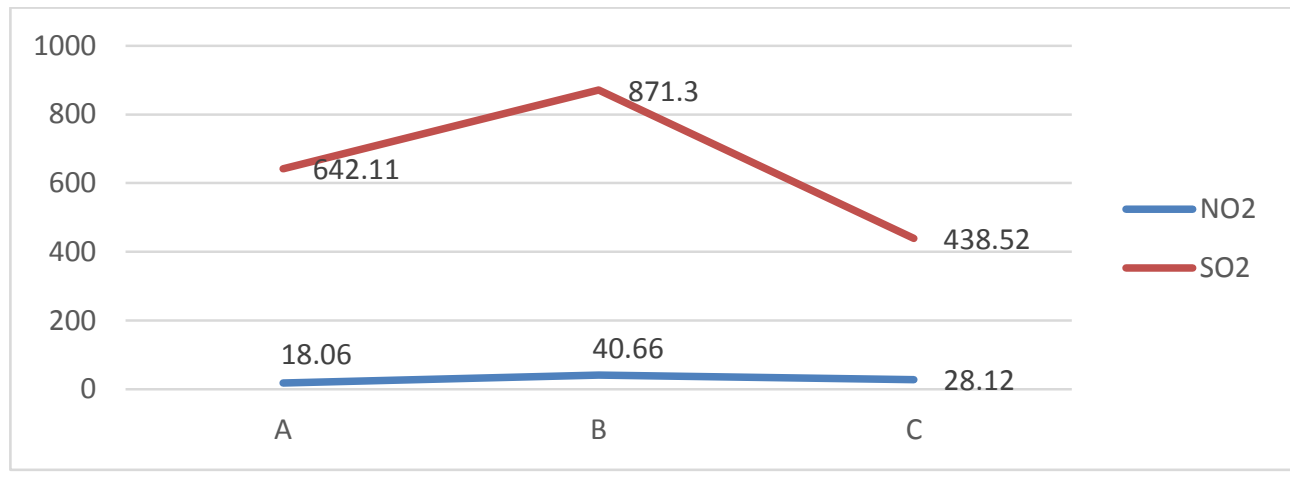

Figure 8: variation of nitrates and suiphates content in the sites of taking away

Concerning the chemical demand for oxygen (DCO), the contents are high for a river and prove that there is pollution with reflect on the capacity of car - purification, i.e. the normal process of regulation for the river vis-a-vis pollution. These values are very high at the point $\mathrm{B}(81,40 \mathrm{mg} / \mathrm{L})$, at the outlet of the hospital and at point A upstream of the hospital, that is to say $76,04 \mathrm{mg} / \mathrm{L}$. The point $\mathrm{C}$ (downstream from the hospital) has a minimal value compared to all the other points, that is to say $68,32 \mathrm{mg} / \mathrm{L}$.

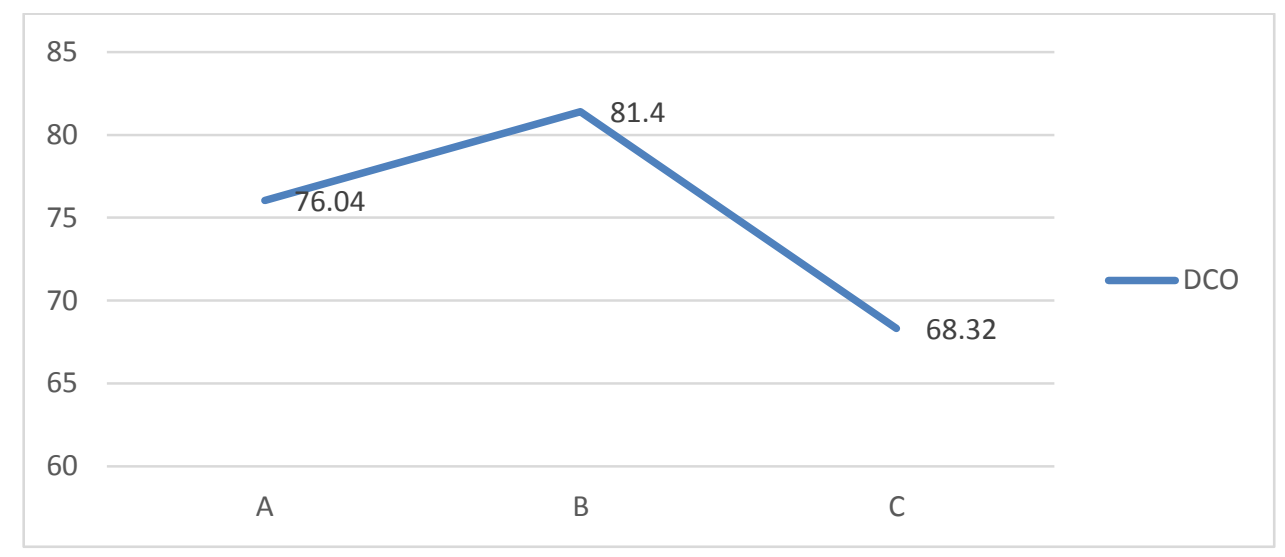

Figure 9: variation of DCO content in the sites of taking away

The biological request oxygenates some during 5 days (DBO5) present of the contents higher than the standards of WHO showing than the water of this river is strongly polluted especially when it receives the effluents of the hospital. The highest value is 
observed at the point $\mathrm{B}$ (outlet of the hospital) either $62,42 \mathrm{Mg}$ of $\mathrm{O}_{2} / \mathrm{L}$, follow-up of the point $\mathrm{C}$ downstream from the hospital, or $48,30 \mathrm{Mg}$ of $\mathrm{O}_{2} / \mathrm{L}$. The point A which is upstream of the hospital, presents a value lower compared to the other points, that is to say 45,61 $\mathrm{Mg}$ of $\mathrm{O}_{2} / \mathrm{L}$. this value is also higher than the standards. Compared to the regulation of WHO, one could say that this river is strongly polluted and separately the hospital, there are also other sources of pollution not identified upstream.

So it causes: the harmful effect, destruction of the rivers, the pollution of the ground water, etc.

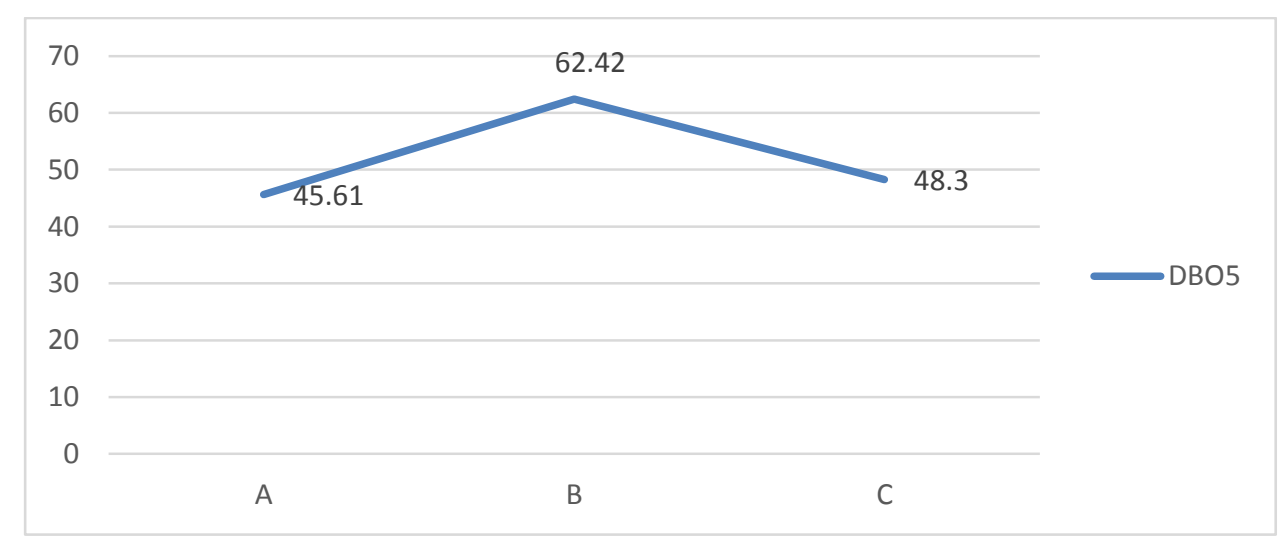

Figure 10: variation of DBO5 content in the sites of taking away

\section{GENERAL CONCLUSION}

The present study consists with the physicochemical characterization of the effluents of the General Hospital of Reference of the zone of Wangata Health/Ville of Mbandaka and to see its impacts on the river Botema Bofala Nkele.

To this end, a matrix was studied, namely water. The latter is regarded as the tank to which are conveyed the majority of the contaminants.

The physicochemical analyses, reveal that the quality of water of the river Botema Bofala Nkele is not good. Indeed, the temperature is high, dissolved oxygen is beyond and that is felt with by the comparison to the standard of WHO. The highest value is upstream of the hospital, follow-up of the outlet and lower value downstream from the General Hospital of Reference of the zone of Wangata Health.

The results also show that water of the river Botema Bofala Nkele is very charged in suspended matter, especially that they receive the effluents of the hospital, the not controlled discharges and the domestic effluents of the surrounding population. Indeed, all the results obtained are except standards with share the $\mathrm{pH}$.

The problem of hospital rejection of the effluents being alarming, we estimate that their treatment is of capital importance before their rejection in the receiving medium in order to guarantee the protection of the public health and the improvement of the conditions of the environment.

Have regard by what precedes, it is appropriate that the provincial government of Ecuador is implied personally to seek solutions and to even impose severe rules on any pollutant to safeguard our inheritance in full degradation.

\section{REFERENCES}

1. ANDREANNE DEMERS (2008), Les eaux usées : une pollution encore et toujours à la une, Thèse de Doctorat

2. MALIANI K., OTAMONGA J.P., NGELINKOTO P., KABATUSUILA P., MUBEDI ILUNGA J. (2017). Caractérisation physico-chimique de l'eau de la rivière Lukunga dans la ville de Kinshasa (R. D. DU CONGO), Larhyss Journal, no 29, pp 121-136.

3. ADEM AMINA AMEL (2011) Impact des rejet des eaux usées sur le littoral Algérois, constat et diagnostic de la situation actuelle, Mémoire de master, Ecole nationale Supérieur des sciences de la Mer et de l'Aménagement du Littoral, Algérie.

4. W.H.O. (1987). Global pollution and health results of related environmental monitoring. Global Environment Monitoring system, WHO, UNEP

5. RODIER J., (1976). L'analyse de l'eau. “Eau naturelle, eau résiduaire, eau de mer." 5 ${ }^{\text {ème }}$ Ed. Dunod, Paris, France, 1600p 
6. BONTE SL., M. PONS, O. POTIER, P. ROCKLIN. (2008), "Relation between Conductivity and Ion Content in Urban Wastewater" Journal of Water Science, vol. 21, n 4, 429- 438

7. ABDOULAYE DEMBA N'DIAYE, KHADIJETTOU MINT MOHAMED SALEM, MOHAMED OULD SID'AHMED OULD KANKOU. (2012). Contribution à l'étude de la qualité physico-chimique de l'eau de la rive droite du fleuve Sénégal, Larhyss Journal, ${ }^{\circ} 12$, p. 71-83.

8. CHAPMAN D., KIMSTACH V. (1996). Selection of water quality variables. Water quality assessments: a guide to the use of biota, sediments and water in environment monitoring, Chapman edition, 2nd ed. E and FN Spon, London, pp. 59126.

9. BELGHITI M. L., CHAHLAOUI A., BENGOUMI D., EL MOUSTAINE R. (2013). Etude de la qualité physicochimique et bactériologique des eaux souterraines de la nappe plio-quaternaire dans la région de Meknès (Maroc), Larhyss Journal, no 14, pp 21-36

10. UDERT KM., TA. LARSEN, M. BIEBOW, W. GUJER. (2003). Urea hydrolysis and precipitation dynamics in a urine collecting system. Water Res., 37, 2571" 2582

11. Belghiti M. L., CHAHLAOUI A., BENGOUMI D., EL MOUSTAINE R. (2013). Etude de la qualité physicochimique et bactériologique des eaux souterraines de la nappe plio-quaternaire dans la région de Meknès (Maroc), Larhyss Journal, no 14, pp 21-36

12. DOUBI M., DERMAJ A., AIT HADOU B., CHEBABE D., ERRAMLI H., HAJJAJI N., ABDELLAH SRHIRI A. (2013). Contribution à l'étude physico-chimique de l'oued Moulouya et un affluent au niveau de la région d'Outat El Haj, Larhyss Journal, no 16, pp. 91-104

13. HAMMOUDA N., (2013). Contribution à l'étude de l'effet de l'action anthropique sur les zones humides du Sud-est du Sahara (Cas de l'Oued Righ). Mémoire de master Académique. Université d'Ouargla. pp 19-23.

14. MAKHOUKH M., SBAA M., BERRAHOU A., VAN CLOOSTER M. (2011). Contribution à l'étude physico-chimique des eaux superficielles de l'Oued Moulaya (Maroc Oriental), Larhyss Journal, no 09, pp. 149-169.

15. AVERY S.T. et P. NOVAK (1978). Oxygen transfer at hydraulic structures. J. Hydraul. Div., ASCE, 104, $1521-1540$.

16. BAYLAR A., M. UNSAL et F. OZKAN (2011). GEP modeling of oxygen transfer efficiency prediction in aeration cascade. KSCE, J. Civ. Eng., 15, 799-804.

17. BAYLAR A., T. BAGATUR et E. EMIROGLU (2007). Prediction of oxygen content of nappe, transition and skimming flow regimes in stepped-channel chutes. J. Environ. Eng. Sci., 6, 201-208. 